\title{
Trehalose: As Sweet as Effective in Biomedical Research and Biotechnology
}

\author{
Elis Cristina Araujo Eleutherio*, Aline Araújo Brasil, Germana Breves Rona and Rayne Stfhany Silva \\ Magalhães \\ Institute of Chemistry, Federal University of Rio de Janeiro, Brazil
}

Submission: January 27, 2018; Published: March 20, 2018

*Corresponding author: Elis Eleutherio, Departamento de Bioquímica - Universidade Federal do Rio de Janeiro. Av. Athos da Silveira Ramos, no149, Bloco A-sala 547 CEP: 21941909 Centro de Tecnologia, Cidade Universitária, Rio de Janeiro-RJ, Brazil, Tel: +552139387260,

Email: eliscael@iq.ufrj.br

\begin{abstract}
Since the trehalose discovery, this disaccharide has been reported to accumulate in anhydrobiotic organisms which are able to survive completely dry and dormant until living conditions improve. Trehalose has been widely studied to understand its function and abundance in nature due to its unique features, including the ability to sustain and preserve a wide array of biological molecules. In face of these physical and chemical properties, this sugar has been used in a variety of food, medical and cosmetic products as well as in many biomedical researches. Currently, there is a growing interest in the use of trehalose as a relevant therapeutic agent in neurodegenerative disorders such as Alzheimer's, Huntington's and Parkinson's diseases as well as in the modification of trehalose molecule into novel inhibitors of cancer cell migration and invasion. These current applications have proven possible because of the trehalose ability to enhance autophagic activity, respond against a variety of environmental stressors and stabilize protein folding mechanisms. This brief review highlights the promising biotechnological and biomedical applications of trehalose.
\end{abstract}

Keywords: Trehalose; Microorganisms; Biotechnology

Abbreviations: T6P: Trehalose-6-Phosphate; Tps1: Trehalose synthase; Ath1: Acid trehalase; HD: Huntington's disease; PD: Parkinson's disease; AD: Alzheimer's Disease; ROS: Reactive Oxygen Species; PoliQ: Polyglutamine; LBD: Lewy body disease; APP: Amyloid Precursor Protein; ER: Endoplasmatic Reticulum; OTSA: Trehalose-6-phosphate synthase

\section{Introduction}

Trehalose is a non reducing disaccharide composed of two residues of glucose joined through 1,1- $\alpha, \alpha$-glycosidic linkage $[1,2]$. This sugar is found in bacteria, fungi, plants, insects, and invertebrates, but not in vertebrates [3,4]. Humans have the ability to hydrolyze but not to synthesize treahlose. The main functions of trehalose are to confer protection against stress and to serve as fuel reserve [5]. The first recorded information of trehalose was in cocoons of Larinus beetles in 1681, and in 1953, Leloir and Cabib elucidated for the first time the complete metabolic pathway of trehalose. Trehalose can be biosynthesized by five pathways. It can be produced by the trehalose-phosphate synthase/trehalose phosphatase pathway in yeast, bacteria, archaea, insects, and plants.

Archaea, like Hyperthermophilic archeae, Pyrococcus horikoshii, Thermococcus litoralis, Thermoproteus tenax can also convert glucose and UDP-glucose into trehalose using trehalose-synthesizing glycosyltransferase [6]. Through the TreY/TreZ pathway Sulfolobus and Mycobacterium can convert malto oligosaccharides into trehalose [2]. Malto oligosaccharides and maltose can also be converted to trehalose by the trehalose synthase pathway in some bacteria [7]. The fifth biosynthetic pathway converts glucose and glucose-1-phosphate in trehalose using trehalose phosphorylase in bacteria, yeast and fungi, for example Bacillus stearothermophilus, Thermoanaerobacter brockii and Copelatus subterraneus [6]. In face of the interesting properties of trehalose, its role and metabolism have been investigated since a long time. However, there are still questions to be answered. Recently, Arthrobacter was used as a model to analyze development switches caused by the environment. This is possible because of its resistance to stress, probably related to their pleomorphic behavior. Trehalose-6-phosphate synthase (otsA) of Arthrobacter is probably involved in cellular morphology, representing an adaptation of bacteria that survive in extreme environments [8].

The protective effect of trehalose on Rhodobacter sphaeroides has also been presented. It was shown that a trehalose matrix 
is able to protect the centers reactions of photosynthetic protein complexes against dehydration, leading to a greater maintenance of its photochemical activity [9]. Saccharomyces cerevisiae, Candida albicans, and Candida Tropicalis were used as experimental models to show the ability of Trehalose-6Phosphate (T6P) to inhibit trehalose synthase (Tps1) activity. In this way, T6P reduced the trehalose synthesis that is directly related to the virulence of some pathogens [10]. The protective effect of trehalose on Aureobasidium subglaciale, a fungus collected on soil contaminated with radiation and heavy metals, has already been demonstrated. In this study, a strain with three fold higher trehalose production, due to overexpression of Tps1 and the deletion of acid trehalase (Ath1), showed greater resistance against heavy-metal and radiation than the control strain. This data leads to the conclusion that there is a relationship between trehalose accumulation and the oxidative stress response in Aureobasidium subglaciale [11]. Subheading: Biotechnology Applications of Trehalose More than a decade after the liberation of the use of trehalose in humans by the United States and the European Union, which classified trehalose as safe, the studies about this sugar are increasingly focused on its beneficial properties for humans [12]. Those properties are mainly related to the trehalose structure, specifically on the interaction between the two molecules of glucose and its function as a kosmotrope [13]. These properties are important for the protective roles against stress, as oxidative stress, heating and starving. Furthermore, trehalose is synthetized in a wide range of organism, other than humans, which lack TPS enzyme, necessary for trehalose production [5]. Since trehalose is able to stabilize the structure of biomolecules (proteins, enzymes, DNA) and macrostructures (lipid bilayer) and to avoid protein aggregation during denaturating conditions, it has been intensively investigated for application in the treatment of infectious diseases, caused by pathogens whose virulence depend on trehalose synthesis, neurodegenerative diseases and cancer $[10,14]$. On the other hand, some groups are developing methodologies to introduce trehalose in different areas, as cosmetics (development of bath oils, moisturizers, due to its role as protection against dehydration); pharmaceutical applications (as component in medicines to treat high blood pressure, due to its role to protects against osmotic stress) [14]. Trehalose can be found in some methods to produce and preserve dried vegetables and fruits, in the production of Swiss cheeses and as sweetener $[15,16]$. One of the problems faced during therapeutic treatment, which use drugs that need to be delivered inside the organism, is how to introduce this component without side effects to the organism and with high rates of absorption. An alternative for oral delivery and parenteral methods is the use of biodegradable microneedles. Some studies are focused in the use of trehalose during the creation of these needles due to its capacity of interaction with the biomolecules, producing a sugar glass layer, and then, protecting the structure against composition alterations during its development before their use in humans [17].
Due to its cryoprotective and preservative role, trehalose can be found in solutions of organs transplantation, development of vaccines, antibodies, and during skin treatment with antiinflammatory drugs, where trehalose is used to reduce the side effects, as cutaneous irritation [15,18].

\section{Trehalose as a therapeutic candidate ready to enter clinical trials}

Trehalose also displays a number of remarkable qualities including the ability to protect the integrity of cells against desiccation, heat, cold and oxidation(5). Moreover, trehalose may act as a chemical chaperone, preserving protein structure stability, protein folding as well as reducing aggregation of pathologically misfolded proteins $[19,20]$. Oxidative stress, aggregation and proteasomal dysfunction have been considered key mechanisms associated with neurodegenerative disorders, including Huntington's disease (HD) [21], Parkinson's disease (PD) [22] and Alzheimer's disease (AD) [23,24]. It was recently reported the treatment with trehalose was able to counteract the increase in reactive oxygen species (ROS), ubiquitinated proteins, huntingtin and activated caspase- 3 levels induced by the inhibitor of proteasome activity epoxomicin. The authors also pointed out the valuable effects of this disaccharide in proteinopathies, as an autophagy enhancer, chemical chaperone, antioxidant and an interesting therapeutic candidate for testing in HD patients [21].

By using in vitro and in vivo models of HD, other studies have shown the trehalose was able to inhibit polyglutamine (poliQ) mediated aggregation $[25,26]$. Recent studies demonstrate that trehalose protects dopaminergic neurons in the striato-nigral pathway from the pathological symptoms induced by MPTP (eg. vessel regression and ischemia) in mouse models of Parkinson's disease [27]. Other study currently highlighted the ability of the autophagy enhancer, trehalose to protect against A53T $\alpha$-synuclein mediated dopamine degeneration in a rat model of PD [28]. Trehalose intake has increased levels of chaperone molecules, such as Hsp 90 and SigmaR1 along with autophagy in brains of model mice of Lewy body disease (LBD). It has also been reported in this study that oral administration of trehalose suppressed the levels of detergent-insoluble $\alpha$-synuclein in mice [29]. As such, in Alzheimer's disease, trehalose promotes the cellular clearance of the phosphorylated pathogenic tau protein [30-32]. In addition, cell treatment with trehalose was capable to alter vesicular trafficking, thereby decreasing the degradation of Alzheimer-associated Amyloid Precursor Protein (APP) in endolysosomal compartments and the secretion of amyloid- $\beta$ peptide [33]. The role of trehalose in reducing $A \beta$ peptide aggregation is still unclear, however a very recent study concluded that trehalose affects the conformation of $A \beta$ peptide to form $\alpha$-helical structure, which may prevent the formation of $\beta$-sheets and thereby aggregation [34].

The autophagic effects of trehalose together with its antiapoptotic property on tumor cells and lack of toxicity on 
normal cells has been recently used as a Potential neoadjuvant for antitumor drugs for treating several cancers [35]. Other medically property of trehalose include the suppression of the osteoarthritis (OA) [36], herpesviruses [37] and age-associated liver injuries [38] mainly through the elimination of oxidative stress, reduction of endoplasmatic reticulum (ER) stress and autophagic flux restoration [36].

\section{Conclusion}

Since trehalose's discovery, this disaccharide has been widely studied due to its interesting and unique properties. It was formerly focused on the better understanding of the pathways of synthesis and its role in the microorganisms that synthesized it. In the last decade, research involving trehalose has increased focusing on its application in the food, pharmaceutical, and cosmetics industry. Based on the results obtained so far using different models, and the advance of new research techniques, more studies are on the way to find more applications of this interesting and versatile sugar.

\section{Acknowledgement}

This review was supported by grants from FAPERJ, CAPES and CNPq.

\section{References}

1. Thammahong A, Puttikamonkul S, Perfect JR, Brennan RG, Cramer RA (2017) Central role of the trehalose biosynthesis pathway in the pathogenesis of human fungal infections: opportunities and challenges for therapeutic development. Microbiol Mol Biol Rev 81(2): e00053-e000116.

2. O Neill MK, Piligian BF, Olson CD, Woodruff PJ, Swarts BM (2017) Tailoring trehalose for biomedical and biotechnological applications. Pure Appl Chem 89(9): 1223-1249.

3. Singer MA, Lindquist S (1998) Thermotolerance in Saccharomyces cerevisiae: the Yin and Yang of trehalose. Trends Biotechnol 16(11): 460-468.

4. Benaroudj N, Lee DH, Goldberg AL (2001) Trehalose accumulation during cellular stress protects cells and cellular proteins from damage by oxygen radicals. J Biol Chem 276: 24261-24267.

5. Eleutherio E, Panek A, De Mesquita JF, Trevisol E, Magalhães R (2015) Revisiting yeast trehalose metabolism. Curr Genet 61(3): 263-274.

6. Walmagh M, Zhao R, Desmet $\mathrm{T}$ (2015) Trehalose analogues: latest insights in properties and biocatalytic production. Int J Mol Sci 16: 13729-13745.

7. Nishimoto T, Nakano M, Nakada T, Chaen H, Fukuda S, et al. (1996) Purification and properties of a novel enzyme, trehalose synthase, from Pimelobacter sp. R48. Biosci Biotechnol Biochem 60(4): 640-644.

8. Chen X, An L, Fan X, Ju F, Zhang B, et al. (2017) A trehalose biosynthetic enzyme doubles as an osmotic stress sensor to regulate bacterial morphogenesis. PLoS Genet 13: e1007062.

9. Knox PP, Lukashev EP, Seifullina NK, Gorokhov VV, Rubin AB (2017) Influence of trehalose on high-temperature stability of the photosynthetic reaction centers. Dokl Biochem Biophys 477(1): 368371.

10. Magalhães RSS, De Lima KC, De Almeida DSG, De Mesquita JF, Eleutherio ECA (2017) Trehalose-6-Phosphate as a potential lead candidate for the development of tps1 inhibitors: insights from the trehalose biosynthesis pathway in diverse yeast species. Appl Biochem Biotechnol 181(3): 914-924.

11. Liu T, Zhu L, Zhang Z, Huang H, Zhang Z, et al. (2017) Protective role of trehalose during radiation and heavy metal stress in Aureobasidium subglaciale F134. Sci Rep 7(1): 17586.

12. Yang S, Lv X, Wang X, Wang J, Wang R, et al. (2017) Cell-surface displayed expression of trehalose synthase from pseudomonas putida atcc 47054 in pichia pastoris using pir1p as an anchor protein. Front Microbiol 8: 2583.

13. Cray JA, Russell JT, Timson DJ, Singhal RS, Hallsworth JE (2013) A universal measure of chaotropicity and kosmotropicity. Environ Microbiol 15(1): 287-296.

14. Jain NK, Roy I (2009) Effect of trehalose on protein structure. Protein Sci 18(1): 24-36.

15. Pawlicka kaczorowska J, Czaczyk K (2017) Effect of crude and pure glycerol on biomass production and trehalose accumulation by Propionibacterium freudenreichii ssp. Acta Biochim Pol 64(4): 621629.

16. Yan X, Zhu L, Yu Y, Xu Q Huang H, et al. (2018) In situ biocatalytic production of trehalose with auto-induction expression of trehalose synthase. J Agric Food Chem 66(6): 1444-1451.

17. Martin CJ, Allender CJ, Brain KR, Morrissey A, Birchall JC (2012) Low temperature fabrication of biodegradable sugar glass microneedles for transdermal drug delivery applications. J Control Release 158(1): 93101.

18. Kayasuga Kariya Y, Iwanaga S, Fujisawa A, Lin LS, Suzuki S (2013) Dermal cell damage induced by topical application of non-steroidal anti-inflammatory drugs is suppressed by trehalose co-lyophilization in Ex Vivo analysis. J Vet Med Sci 75(12): 1619-1622.

19. Upagupta C, Carlisle RE, Dickhout JG (2017) Analysis of the potency of various low molecular weight chemical chaperones to prevent protein aggregation. Biochem Biophys Res Commun 486(1): 163-170.

20. Portbury SD, Hare DJ, Finkelstein DI, Adlard PA (2017) Trehalose improves traumatic brain injury-induced cognitive impairment. PLoS One 12(8): e0183683.

21. Fernandez-Estevez MA, Casarejos MJ, Sendon JL, Caldentey JG, Ruiz C, et al. (2014) Trehalose reverses cell malfunction in fibroblasts from normal and huntington's disease patients caused by proteosome inhibition. PLoS One 9(2): 1-9.

22. Liu Z, Zhou T, Ziegler AC, Dimitrion P, Zuo L (2017) Oxidative stress in neurodegenerative diseases: from molecular mechanisms to clinical applications. Oxid Med Cell Longev 2017: 2525967.

23. Hartl FU (2017) Protein misfolding diseases. Annu Rev Biochem 86: 21-26.

24. Hartl FU, Bracher A, Hayer-Hartl M (2011) Molecular chaperones in protein folding and proteostasis. Nature 475(7356): 324-332.

25. Sarkar S, Davies JE, Huang Z, Tunnacliffe A, Rubinsztein DC (2007) Trehalose, a Novel mTOR-independent Autophagy Enhancer, Accelerates the Clearance of Mutant Huntingtin and $\alpha$-Synuclein. J Biol Chem 282: 5641-5652.

26. Tanaka M, Machida Y, Niu S, Ikeda T, Jana NR, et al. (2004) Trehalose alleviates polyglutamine-mediated pathology in a mouse model of Huntington disease. Nat Med 10(2): 148-154.

27. Sarkar S, Chigurupati S, Raymick J, Mann D, Bowyer JF, et al. (2014) Neuroprotective effect of the chemical chaperone, trehalose in a chronic MPTP-induced Parkinson's disease mouse model. Neurotoxicology 44: 250-262. 
28. He Q Koprich JB, Wang Y, Yu WB, Xiao BG, et al. (2016) Treatment with Trehalose prevents behavioral and neurochemical deficits produced in an aav $\alpha$-synuclein rat model of parkinson's disease. Mol Neurobiol 53(4): 2258-2268.

29. Tanji K, Miki Y, Maruyama A, Mimura J, Matsumiya T, et al. (2015) Trehalose intake induces chaperone molecules along with autophagy in a mouse model of Lewy body disease. Biochem Biophys Res Commun 465(4): 746-752.

30. Casarejos MJ, Solano RM, Gómez A, Perucho J, de Yébenes JG, et al. (2011) The accumulation of neurotoxic proteins, induced by proteasome inhibition, is reverted by trehalose, an enhancer of autophagy, in human neuroblastoma cells. Neurochem Int 58(4): 512 520.

31. Krüger U, Wang Y, Kumar S, Mandelkow EM (2012) Autophagic degradation of tau in primary neurons and its enhancement by trehalose. Neurobiol Aging 33(10): 2291-2305.

32. Schaeffer V, Lavenir I, Ozcelik S, Tolnay M, Winkler DT, et al. (2012) Stimulation of autophagy reduces neurodegeneration in a mouse model of human tauopathy. Brain 135: 2169-2177.

33. Tien NT, Karaca I, Tamboli IY, Walter J (2016) Trehalose alters subcellular trafficking and the metabolism of the Alzheimer-associated amyloid precursor protein. J Biol Chem 291(20): 10528-10540.
34. Khan SH, Kumar R (2017) Trehalose induced conformational changes in the amyloid- $\beta$ peptide. Pathol Res Pract 213(6): 643-648.

35. El Magd M, Khamis A, Nasr Eldeen SK, Ibrahim WM, Salama AF (2017) Trehalose enhances the antitumor potential of methotrexate against mice bearing Ehrlich ascites carcinoma. Biomed Pharmacother 92: 870-878.

36. Tang Q Zheng G, Feng Z, Chen Y, Lou Y, et al. (2017) Trehalose ameliorates oxidative stress-mediated mitochondrial dysfunction and ER stress via selective autophagy stimulation and autophagic flux restoration in osteoarthritis development. Cell Death Dis 8(10): e3081.

37. Meier JL, Grose C (2017) Variable effects of autophagy induction by trehalose on herpesviruses depending on conditions of infection. Yale J Biol Med 90(1): 25-33.

38. Pagliassotti MJ, Estrada AL, Hudson WM, Wei Y, Wang D, et al. (2017) Trehalose supplementation reduces hepatic endoplasmic reticulum stress and inflammatory signaling in old mice. J Nutr Biochem 45: 1523.

\section{Your next submission with Juniper Publishers will reach you the below assets}

- Quality Editorial service

- Swift Peer Review

- Reprints availability

- E-prints Service

- Manuscript Podcast for convenient understanding

- Global attainment for your research

- Manuscript accessibility in different formats

( Pdf, E-pub, Full Text, Audio)

- Unceasing customer service

Track the below URL for one-step submission https://juniperpublishers.com/online-submission.php 